\title{
Protection Against Malaria in Man: a Probe into Some of the Implicated Mechanisms in Sub-Saharan Africa
}

\author{
Andreas Chiabi ${ }^{1, *}$, Bolaji Obadeyi ${ }^{2}$, Hubert Désiré Mbassi ${ }^{3}$, Liliane Nenwa ${ }^{4}$, Lawrence Mbuagbaw ${ }^{5}$, \\ Evelyn Mah ${ }^{1}$, Dongmo Félicité ${ }^{3}$, Albert Zeh Meka ${ }^{4}$, Joshua Walinjom ${ }^{4}$ and Elie Mbonda ${ }^{1}$ \\ ${ }^{I}$ Yaounde Gynaeco-Obstetric and Pediatric Hospital/Faculty of Medicine and Biomedical Sciences, University of \\ Yaounde I, Cameroon \\ ${ }^{2}$ Health Logics, Lagos, Nigeria \\ ${ }^{3}$ Chantal Biya Mother and Child Centre/Faculty of Medicine and Biomedical Sciences, University of Yaounde I, \\ Cameroon \\ ${ }^{4}$ Faculty of Medicine and Biomedical Sciences, University of Yaounde I, Cameroon \\ ${ }^{5}$ Department of Clinical Epidemiology and Biostatistics, McMaster University, Hamilton, Ontario, Canada
}

\begin{abstract}
Malaria is amongst the most common parasitic infections in the world. In Africa it causes one in every five childhood deaths, with one child dying of malaria every 30 seconds. People living in malaria endemic areas appear to have protective immune mechanisms, which may be naturally occurring or acquired from exposure to the malaria parasite. These protective factors play an important role in reducing morbidity and mortality from malaria. This review is aimed at exploring and explaining the mechanisms for a selection of the main protective factors to malaria in man. Using an extensive literature review of prominent articles, this paper identifies and summarizes these mechanisms which may be acquired or genetic. The challenge for the future will be to translate these notions into the development of interventions for the prevention and treatment of malaria.
\end{abstract}

Keywords: Malaria, protective mechanisms, immunity.

\section{INTRODUCTION}

Malaria is the most common cause of ill health and death in Africa and remains a major factor limiting economic growth and development on the continent. It is a significant global public health challenge with 216 million cases and 655,000 deaths estimated in $2010,86 \%$ of which were in infants below the age of 5 years living mostly in the African region [1].

From a historical perspective, man and Plasmodium falciparum have been co-existing since the onset of the practice of agriculture about 10, 000 to 20, 000 years ago. By domesticating plants and animals, man became exposed to one of the major vectors of malaria, the Anopheles gambiae sl complex. The biological interaction between man and the malaria parasite may have resulted in selective pressure exerted by the parasite on the human genome such that some persons in malaria infected areas now demonstrate selective protective advantages against severe and lethal strains of malaria [2].

*Address correspondence to this author at the Yaounde Gynaeco-Obstetric and Pediatric Hospital/Faculty of Medicine and Biomedical Sciences, University of Yaounde I, Cameroon, P.O. Box 4362, Yaounde, Cameroon;

Tel: 00237995983 71; Fax: 00237222124 30;

E-mail: andy_chiabi@yahoo.co.uk
In pregnant women, children and non-immune individuals a more severe form of malaria is experienced. In particular, some persons appear to have a genetic or immunologic predisposition to having less frequent and milder episodes of malaria raising the question of naturally occurring or acquired immune protective mechanisms expressed in some groups of persons.

In this article, we revisit some of these observed genetic and acquired mechanisms responsible for protection against malaria. In spite of the decline in the burden of malaria, we believe there is a need to have a revised and collated understanding of the role and possibly the magnitude of the effect of these protective mechanisms in further reducing the burden of malaria.

To conduct this review, a comprehensive search of the US National Library of Medicine data base-PubMed and Google Scholar was carried out without date restrictions. Peer-reviewed articles describing the immune protective mechanisms in malaria were identified and used for this review. Various combinations of the following search terms were employed: malaria, plasmodium, immunity, protection, mechanism. The websites of relevant scholarly societies such as the World Health Organization were consulted for information and additional citations. 


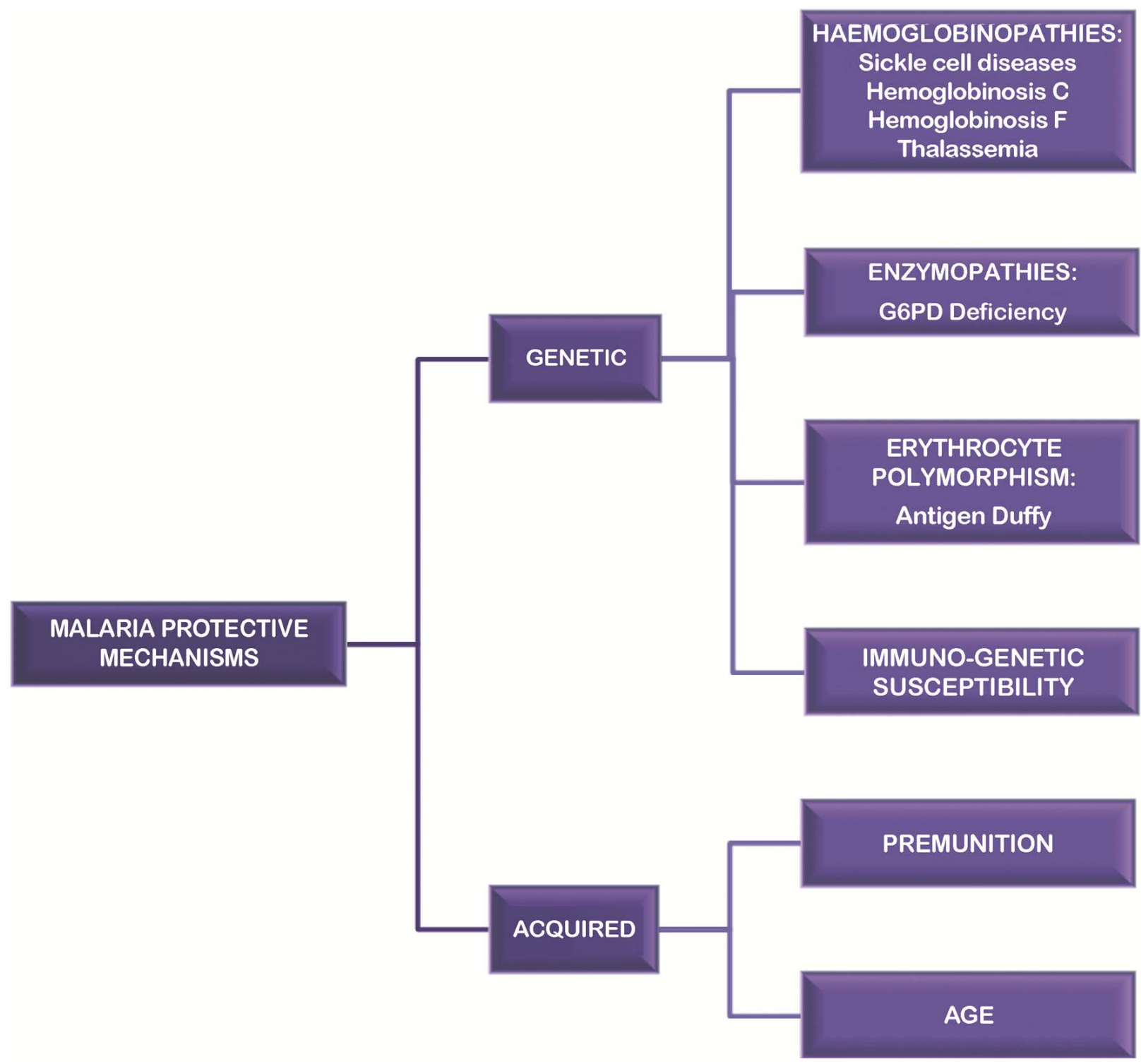

Fig. (1). Outline of protective mechanisms against malaria.

\section{PHYSIOLOGY OF THE RED BLOOD CELL IN MA- LARIA INFECTION}

Part of the life cycle of the parasite responsible for malaria, Plasmodium spp, occurs in mature erythrocytes. The symptoms of malaria manifest when parasites invade a red blood cell (RBC) consuming its hemoglobin and multiplying to produce 8-32 'daughters' or merozoites inside the cell [3]. Development and multiplication of the parasite within normal red blood cells induces marked cellular modification that further favors division of the microbe [4]. At this stage host cell receptors and the proteins of the parasite interact, resulting in striking structural, biochemical and functional changes in the red blood cells e.g. parasite- induced loss of integrity in the RBC membrane. These modifications include increased membrane rigidity, reduced cell flexibility and greater adhesiveness to the vascular endothelium [5]. Of particular importance for understanding the protective mechanisms involved are the observed alteration of membrane protein organization and exportation of plasmodium protein which interferes with the adhesive and mechanical properties of RBCs.

Moreover, these physiological changes result in increased sequestration and lysis of parasitized RBCs in very small blood vessels accounting for clinical syndromes such as anemia and cerebral malaria [5].

\section{MALARIA PROTECTIVE MECHANISMS}

Infection with the plasmodium parasite and the subsequent multiplication of the parasite within the RBCs can lead to disease and death of the host. On the other hand, the host could have innate protective mechanisms or acquire such mechanisms from repeated exposure over time. Such immunity may deter or inhibit parasite growth and multiplication, reducing the severity of disease and risk of death thus offering some protection against this deadly disease. While everyone in a malaria endemic area has the opportunity to develop acquired immunity from continuous exposure and repeated malaria infection, only a number of persons at risk 
have genetically determined or innate immunity to the disease.

Our review categorizes protective mechanisms under two broad headings, which are commonly encountered mechanisms in our area of practice and each of which is further explored as outlined below (Fig. 1).

A. Genetic protective mechanisms: hemoglobinopathies, enzymopathies, erythrocyte polymorphisms, and immunogenetic susceptibility.

B. Acquired protective mechanisms: premunition, and age.

\section{GENETIC PROTECTIVE MECHANISMS}

\section{Hemoglobinopathies}

Although several hemoglobin syndromes have been described, the clinically important hemoglobin syndromes result from single amino acid substitutions in the $\alpha$ or $\beta$ chains of adult hemoglobin. This section will examine the impact of malaria on the homozygous disease and present key evidence for the protective state conferred by the heterozygous state.

\section{Sickle Cell Disease (SCD)}

In some African countries like Cameroon, the Republic of Congo, Gabon, Ghana and Nigeria, the prevalence of sickle cell disease ranges from $20 \%$ to $30 \%$, while in some parts of Uganda it is as high as $45 \%$. In countries where the prevalence of the trait is high (above 20\%), the disease affects $2 \%$ of the population [6].

SCD is a hereditary disease with recessive autosomal transmission. Despite its ubiquitous character, it affects mostly persons of African origin [7]. The co-occurrence in Africa of the zones of severe malaria and those where sickle cell mutation is endemic has been known for a long time [8]. It is characterized by an abnormal structure of the hemoglobin molecule, in which glutamic acid on position 6 on the $\beta$ chain is replaced by valine. This minor substitution has profound physiological implications. Low oxygen states result in stacking of sickle hemoglobin molecules and distortion of the RBC membrane forming a sickle shaped cell. In the homozygous state, there is a resultant chronic hemolytic anemia which when complicated by malaria increases mortality from this disease. The heterozygous variant runs a benign clinical state and is believed to confer a degree of resistance to malaria. A selective role for Plasmodium provides a survival advantage to the sickle cell trait (AS) heterozygotes while the patients with the sickle cell disease (SS) usually die prematurely [9]. This observation suggests that the $\mathrm{S}$ hemoglobin may confer an advantage in malaria endemic areas. In effect, homozygotes (HbSS) die from sickle cell disease complications, and heterozygotes (HbAS) are resistant to malaria $[10,11]$.

The possible hypotheses of this observation can be explained from cellular, biochemical and polymorphic adaptations and explained as follows:

\section{Cellular Adaptations}

The RBC of sickle cell carriers when affected by plasmodium adhere less to the vascular endothelium and this has been described as the impaired cyto-adherance phenomenon.
The RBC also shows a weak expression of Plasmodium falciparum erythrocyte membrane protein 1(pfEMP-1) on its surface (impaired rossetting) compared to normal AA RBCs. This pfEMP-1 is a key virulent factor for Plasmodium falciparum infection. This protein is expressed on the surface of infected erythrocytes and directly mediates adhesion to a variety of host cells [12].

\section{Biochemical Adaptations}

During sickling, there is potassium loss due to two mechanisms:

- Increase in the activity of the $\mathrm{K}^{+}-\mathrm{Cl}^{-}$co-transporter, with subsequent efflux of potassium and chloride.

- Increase in the activity of the calcium-potassium dependent channel (Gardos effect), due to the transient increase in calcium concentration in the cell during sickling.

The osmotic loss of water resulting from the loss in potassium increases the concentration of $\mathrm{HbS}$ in the cell as well as its polymerization. Both the water loss, and increased polymerization during these pathological processes are the main determining factors inhibiting growth of the parasite in the cell [13]. It is also thought that the activation of the anionic channels and non selective calcium permeable channels by Plasmodium falciparum in infected erythrocytes, stimulates bi-directional phospholipid migration across the bilayer. This results in phospholipid asymmetry of the cell membrane. The end point is the binding of the phospholipid receptors on to macrophages with subsequent phagocytosis of the affected red blood cells. This accelerated red blood cell "apoptosis" may indicate a variety of defense mechanisms of the host which will serve to eliminate the infected red blood cells. This accelerated erythrocyte "apoptosis" may represent a host defense mechanism serving to eliminate infected erythrocytes [14].

\section{Polymorphic Adaptations}

The malaria parasite upon entering a RBC, destroys the hemoglobin thus reducing oxygenation and deforming the cell. There is consequently an increase in the rate of destruction of sickled RBCs in malaria. Repeated infection appears to confer some measure of immunity because of the increased parasite clearance along with deformed $\mathrm{RBC}[7,10$, 13]. Since the non-parasitized RBCs are dominant, the individual's chances of survival increase because the malaria parasites are regularly eliminated. The heterozygous state (HbAS) benefits from this protective mechanism and therefore confers a greater probability of survival from malaria compared to the homozygous state (HbAA or HbSS) where parasitic infestation is higher and fatal complications of malaria are more likely because of the lack of protection $[7,10$, 15].

From the above mechanisms the resulting effect is that the persons in the homozygous state HbSS and HbAA have higher malaria-associated morbidity and mortality [15].

From a different perspective, Fereira et al. reported that sickle $\mathrm{Hb}$ provokes the expression of the enzyme heme oxygenase-1 (HO-1) in hematopoietic cells, through a mechanism which involves the transcription factor NF-E2-related factor 2 (Nrf2). Carbon monoxide (CO), which is a byprod- 
uct of heme breakdown, prevents further accumulation of circulating free heme following Plasmodium infection, and this suppresses the pathogenesis of experimental malaria (ECM). In addition, sickle $\mathrm{Hb}$ inhibits activation of pathogenic $\mathrm{CD} 8+\mathrm{T}$ cell recognizing antigens expressed by the Plasmodium [16].

Evidence of both innate and acquired protection against malaria has been demonstrated in sickle cell trait (HbAS) patients. Gong et al, demonstrated that in these patients, innate mechanisms induce reinforced protection against high parasitemia, and reinforced protection against outblown malaria infection, and that acquired immunity from repeated malaria infection further potentiates these effects [17].

\section{Hemoglobinosis C}

Hemoglobinosis $\mathrm{C}(\mathrm{HbC})$ is most frequent in West Africa, with a high prevalence above $25 \%$ in some regions exceeding that of $\mathrm{HbS}$ [18]. Hemoglobinosis $\mathrm{C}$ is a genetic autosomal recessive disease, due to a mutation on the gene of the $\beta$-globin chain. This results in the substitution of glutamic acid by lysin on position 6 of the $\beta$-globin chain in the amino acid sequence. After sickle cell anemia it constitutes the second most frequent hemoglobinosis in West Africa. The highest frequencies are observed in Ghana, Burkina Faso and Benin [19]. $\mathrm{HbC}$ has the property of crystallizing causing some rigidity of the RBCs and therefore early haemolysis.

The protective effect against malaria provided by $\mathrm{HbC}$ was first described in Mali in 1998 [20]. That study revealed that $\mathrm{HbAC}$ was associated with a risk reduction of approximately $80 \%$ of the risk of developing severe forms of malaria. Another study in 2001 reported a $29 \%$ reduction of risk of malaria in heterozygous carriers of $\mathrm{HbAC}$, and $93 \%$ in HbCC homozygous subjects [21]. Rihet et al. in 2004 in Burkina Faso observed a reduction of the incidence of malaria and parasitaemia in $\mathrm{HbC}$ carriers compared to AA subjects [22].

RBCs, which contain hemoglobin $\mathrm{C}$, are more fragile and seem to carry more surface gamma immunoglobulins (IgGs) therefore selectively favoring elimination from the circulatory system through the reticulo-phagocytic system of the spleen [23]. The homozygous $\mathrm{CC}$ have a higher mean corpuscular concentration of $\mathrm{Hb}$ compared to normal RBCs leading to the crystallization of $\mathrm{HbC}$ [24]. RBCs of AC and $\mathrm{CC}$ individuals are more rigid than those of AA subjects [24]. These changes are less observed in the heterozygous state, $\mathrm{HbAC}$, consequently, in contrast to the sickle cell trait the main protective benefit from $\mathrm{HbC}$ appears to be seen in homozygous $\mathrm{CC}$ rather than the heterozygous state.

In spite of these physiologic differences observed in hemoglobinosis $\mathrm{C}$, the possible explanations for the protection it confers are not balanced and appear to be incomplete. However, possible hypotheses include the inability of merozoites to penetrate $\mathrm{RBCs}$ containing $\mathrm{HbC}$, the non-rupture of schizonts in the RBCs containing $\mathrm{HbC}$, and the inhibition of the growth of plasmodium in the RBCs containing $\mathrm{HbC}[25,26]$. Fairhurst et al, demonstrated that in contrast to parasite-infected normal AA erythrocytes, infected AC and CC red blood cells show reduced adhesion to endothelial mono layers expressing CD36 and intercellular adhesion molecule-1 (ICAM-1). They also show impaired rosetting interactions with non-parasitized red cells, and reduced agglutination in the presence of pooled sera from malaria-immune adults. Abnormal cell-surface display of the main cytoadherence ligand, PfEMP-1 ( $P$. falciparum erythrocyte membrane protein-1) correlates with these findings. The abnormalities in PfEMP-1 display are associated with markers of erythrocyte senescence, and are more in $\mathrm{CC}$ than in $\mathrm{AC}$ erythrocytes. Hemoglobin $\mathrm{C}$ might then protect against malaria by reducing PfEMP-1-mediated adherence of parasitized red blood cells, thereby mitigating the effects of their sequestration in the microvasculature [18].

Mockenhaupt et al. in Ghana, showed that natural selection of $\mathrm{Hb} \mathrm{C}$ occurs because of the relative resistance it confers against severe malaria but are against the notion that $\mathrm{Hb}$ C offers resistance to asymptomatic parasitic infection [27].

\section{Hemoglobin F}

Fœtal hemoglobin $(\mathrm{HbF})$ contains a $\gamma$ polypeptide chain in the place of the $\beta$ chain of hemoglobin A. After 8 weeks of gestation, $\mathrm{HbF}$ is the predominant hemoglobin. At 24 weeks, it represents $90 \%$ of total hemoglobin. During the last trimester of pregnancy, a gradual reduction in the hemoglobin $\mathrm{F}$ level is noted, lowering the level of $\mathrm{HbF}$ to $70 \%$ of total hemoglobin. The synthesis of $\mathrm{HbF}$ decreases after birth and only traces are found between 6 and 12 months [28, 29]. Hemoglobin F contains 2, 3-diphosphoglycerate which has a low affinity for oxygen, hence making the environment inside the RBCs unfavorable for the growth of the parasite [28]. Roberts et al., summarize resistance to malaria of normal neonates and infants during the first six months of life by increased malaria invasion rates in $\mathrm{Hb}$ F-containing cells, resulting in fewer parasites available for invasion of the $\mathrm{Hb}$ A-containing cells and slowed growth within the $\mathrm{Hb} F$ cells [11].

\section{Thalassemia}

Hemoglobin is a tetramer responsible for delivering providing and carrying oxygen to all tissues, and in adults consists of $2 \alpha$-globin and $2 \beta$-globin chains. Thalassemias are hemoglobinopathies resulting from alterations in the synthesis of globin chains. While $\alpha$-thalassemia displays an abnormal $\alpha$-globin synthesis, the amount of $\beta$-globin is diminished in $\beta$-thalassemia. Alpha-thalassemia is caused by decreased synthesis of an $\alpha$-globin chain resulting from deletion of the duplicated $\alpha$-globin genes located on chromosome 16, whereas $\beta$-thalassemia is produced by decreased synthesis of $\beta$-globin leading to a relative excess of $\alpha$-globin chains. The $\beta$-globin gene is localized on chromosome $11 \mathrm{p} 15.5$, and is responsible for the synthesis of the hemoglobin's $\beta$-globin polypeptide [16].

Alpha thalassemia and to a lesser degree, beta thalassemia are protective against malarial infection [11]. The mechanism of malaria protection in thalassemia remains putative and very controversial. In thalassemia, it is believed that oxidative stress plays a protective role, given that the hemoglobin is normal, and therefore may not be implicated in its protective mechanism. Also a microcytic polyglobulinemia frequent in thalassemias is the most characteristic sign of $\alpha$ or $\beta$ thalassemia, and this cellular adaptation offers protection against massive destruction and severe anemia. The increased occurrence of microcytosis in homozygous individuals contributes to the protection against severe anemia due to malaria [10]. These microcytic RBCs are more 
resistant in a hypotonic solution and also seem to be more resistant to attacks by sporozoites which cause malaria [11].

Other studies have indicated that Plasmodium-infected $\alpha$ thalassemic erythrocytes bind high levels of antibody sera from malaria-endemic areas (which could be the optimum target for immune responses). Opsonization, complementmediated lysis, antibody-dependant cytotoxicity and inhibition of sequestration of infected red blood cells, are the most frequent potential anti-parasite effector mechanisms which might be promoted by these antibodies. Polymorphism in the complement receptor-1 (CR1) gene leading to a reduced level of CR1 expression in erythrocyte (a polymorphism commonly found in regions of Papua New Guinea) and $\alpha-$ thalassemia are both associated with CR1 deficiency. CR1deficient erythrocytes have shown a marked reduction in their ability to form rosettes [16].

Some reports indicate that protection from malaria may be lost if there is coexistence of sickle trait and $\alpha$-thalassemia through a mechanism not well understood [30].

\section{ENZYMOPATHIES}

\section{Glucose-6-Phosphate Dehydrogenase (G6PD) Deficiency}

About, $7.5 \%$ of the world's population has one of the variants of G6PD deficiency without any clinical manifestations, and about $3.4 \%$ of this population has a potential risk of being symptomatic [31].

About 400 million people worldwide (90\% being males) are affected by G6PD deficiency, mostly in malaria endemic zones and in people originating from these areas [32]. It has a high frequency in the Mediterranean countries, subSaharan Africa, Middle East, and Asia. People of African or Hispanic descent in North and South America, West Indies are equally affected [33]. G6PD deficiency (or favism) is a genetic disease transmitted in a recessive mode on chromosome $\mathrm{X}$, predominant in male children. Females, though rarely affected, may transmit the disease. G6PD plays an important role in the reduction of oxidants, which are indispensible in cellular metabolism and in RBC survival [33,34]. Males are hemizygous for the G6PD gene and can therefore fully express G6PD deficiency. Affected hemizygous males and homozygous females fully experience the deficiency, whereas in heterozygous females the disease has a variable expression, and is often absent or moderate [34].

One peculiar aspect with G6PD deficiency is the protection it confers against malaria and its superimposition on Plasmodium falciparum endemic areas. In G6PD deficiency, the coexistence of a moderate oxidant stimulus increases cellular resistance to the parasite growth. In infectious states, oxidants are released in RBCs leading to membrane alterations with the formation of epitomes familiar with the immune system. In G6PD deficiency, this erythrocyte defense mechanism is weakened making the altered cells vulnerable to hemolysis. This effect is however temporary because the parasite rapidly adapts, though relatively, because it is particularly fragile to oxidant stress. This situation gives the host an advantage during malaria infestation since the parasite is particularly sensitive to oxidants, and the RBCs of G6PD deficient patients, which are rich in oxidants, are a less favorable milieu for its development [32]. Ring-stage parasitized erythrocytes, unlike trophozoite-stage parasitized erythrocytes, are nontoxic to phagocytes, and their increased removal by phagocytosis would reduce maturation to the trophozoite-stage and to schizonts and may contribute to malaria resistance in deficient subjects [35].

Hemizygous males are protected against life-threatening malaria from G6PD deficiency which is influenced by a strong natural selection. Very little or none of such protection occurs in heterozygous females [36]. Contrarily, Clark et al, illustrated in a study in Gambian children, that both G6PD-deficient male hemizygous and female heterozygous individuals are protected from severe malaria [37].

\section{ERYTHROCYTE POLYMORPHISM}

\section{Duffy Antigen}

The Duffy antigens are antigens expressed on red blood cells and other cells in the body acting as a chemokine receptor. The expression, of the Duffy antigens on blood cells is coded by Fy genes (Fya, Fyb, Fyc etc.) [38, 39]. Plasmodium vivax is unique in human malaria infection in that invasion of erythrocytes depends exclusively on the Duffy antigen receptors on the red cell surface. However, it is possible not to have nor express the Duffy antigen on RBCs (Fy-/Fy) [39, 40]. This genotype confers complete resistance to Plasmodium vivax infection. The genotype is very rare in European, Asian and American individuals, but very frequent in populations of the indigenous West and Central Africa. It is thought to be the consequence of very high exposure to Plasmodium vivax in Africa over the past years [39].

It has also been demonstrated that the blood group $\mathrm{O}$ provides some protection against severe falciparum malaria [41-44]. This protective effect of blood group $\mathrm{O}$ operates through the mechanism of reduced $P$. falciparum rosetting (binding of infected to uninfected erythrocytes) [41, 44]. Questions still remain unanswered about the interactions between malaria parasites and other blood group antigens [45]. Panda et al, in India observed that the protective role of the blood group $\mathrm{O}$ and susceptibility of the blood group B to severe disease; and in a further meta-analysis of 19 relevant studies on falciparum malaria and the ABO blood group, the same findings of protection provided by the blood group $\mathrm{O}$ was noted but with susceptibility to the A and AB blood groups [43].

\section{IMMUNOGENETIC SUSCEPTIBILITY}

The human major histocompatibility complex comprises one of the most important elements of the immune system, and is formed by multiple polymorphic genes. Of the different classes of HLA, individuals who are carriers of the class I, HLA antigen Bw53, which occur frequently in sickle cell anemia (SSA), are associated with a low risk of severe malaria $[16,39]$. Indeed, carriers of the HLA-Bw53 have $40 \%$ fewer severe malaria infections than other subjects living under the same conditions [46]. This histocompatibility complex class I molecule is present at the hepatic stage and sporozoite antigens of T-Cells. The class II HLA haplotype, DRB1*1302-DQB1*0501, has also been shown to be associated with a lower susceptibility to severe malaria [16]. From a large case-control study of malaria in West African children in The Gambia it was demonstrated that a human leucocyte class I antigen (HLA-Bw53) and an HLA class II haplo- 
type (DRB1*1302-DQB1*0501), which are frequently encountered in West Africans than in other racial groups, are associated with protection from severe malaria [47]. Hill et al. in another study, in malaria-immune African subjects, with HLA-B53-restricted cytotoxic T lymphocytes noted a conserved nonamer peptide from liver-stage-specific antigen-1 (LSA-1), but no HLA-B53-restricted epitopes were identified. This observation indicates a possible molecular basis for this HLA-disease association and supports the premise of liver-stage-specific antigen- 1 as a candidate for a malaria vaccine [48].

Interleukin-4, encoded by IL4, is produced by activated T cells and accelerates proliferation and differentiation of $\mathrm{B}$ cell producing antibodies. In a study in subjects of the Fulani tribe of Burkina Faso, who have two times less malaria attacks and higher levels of anti-malarial antibodies than their neighboring ethnic groups, it was observed that the IL4-524 $\mathrm{T}$ allele was associated with high titers of antibodies against malaria antigens, and this raised the hypothesis that this could increase resistance to malaria [39].

\section{Acquired Protective Mechanisms}

\section{The State of Premunition Due to Malaria Endemicity}

In regions where transmission is intense and lasts throughout the year, a state of tolerance to the parasite is progressively developed resulting in low parasitemia and the absence of symptoms, referred to as a "state of premunition" $[49,50]$. Its major characteristic as a protective factor is in its slow acquisition, which seems to depend on continuous "pressure" of the parasite on the host immune system. Individuals in a state of premunition are also called "hyperimmune" [49]. This appears gradually over repeated reinfections and develops even earlier when transmission is high and constant. However, it is incomplete and does not confer complete elimination of the parasite reservoir. It is transient, and depends on the presence of the parasite within the host $[50,51]$. This form of protection is therefore rapidly lost when a person leaves a malaria endemic area. The multiplication of the parasite can lead to death of the host, but the latter could develop protective mechanisms, which may, over time, inhibit parasite growth and thus eliminate the antigenic stimulus of protective immunity. The living parasite, could also evolve to bypass the host defense mechanisms. Some regulatory disorders of the immune response favor the development of immunopathological phenomena, which can cause death of the host or limit the growth of the parasite. Hence, a precarious balance is established between the survival of the host and that of the parasite [51]. Two phases involved in the development of premunition are [49]:

- Acquisition of clinical immunity, which protects individuals against severe manifestation of the disease and death.

- Development of anti-parasite immunity, which is responsible for maintaining parasitemia at low levels.

Antibodies seem to play a major role in immunity when the parasite is in the blood. Indeed, passive transfer experiments performed in the sixties and reiterated more recently, showed that antibodies from individuals with premunition could confer protection to other individuals [49]. Antibodies could act either directly, by blocking the invasion of erythro- cytes by merozoites, or in cooperation with monocytes / macrophages through the opsonization and phagocytosis mechanisms of the Antibody Dependent Cellular Cytotoxicity (ADCC) or through mechanisms of Antibody Dependent Cellular Inhibition (ADCI). Through these mechanisms, antibodies contribute to the long-term control of parasitemia in individuals with premunition $[49,50]$. A state of premunition is however not life-long immunity nor sterilizing in type because the parasitemia persists longer than the symptoms and individuals can exhibit relapses or recrudescences or become reinfected [50].

In man then, recurrent infections by the Plasmodium parasite leads to malaria induce progressive modulation of the immune response by the acquisition of protective antibodies, causing immunity to the parasite and characterizing premunition.

\section{Age}

Congenital malaria is very rare, even though pregnant women are particularly susceptible to malaria. The prevalence of malaria placentitis exceeds $30 \%$ in holo- or hyperendemic areas, and approaches this rate even in hypoendemic areas [52]. P. falciparum infection during pregnancy is characterized by the accumulation of trophozoite infected red blood cells in placental intervillous spaces. The parasitized erythrocytes bind to chondroitin sulfate A (CSA), an abundant proteoglycan on the surface of the placental trophoblast. The parasite ligand mediating binding is VAR2CSA, a protein which belongs to the $P$. falciparum erythrocyte membrane protein 1 (PfEMP1) family of surface adhesion antigens. [53-57]. This permits the parasites to cover up a functionally important protein from specific IgGdependent immune attack without compromising its function or susceptibility of the infected erythrocytes being destroyed by complement-mediated lysis [53].

During pregnancy there is a higher risk of Plasmodium falciparum, and this risk decreases with subsequent pregnancies. This is due to the acquisition of parity-dependent antibodies against placental parasites expressing variant surface antigens, VAR2CSA, that modulates placental sequestration through linkage to chondroitin sulfate A (CSA) coupled with a low IgG response [58]. Since this immune response is mounted and increased with subsequent pregnancies, this may explain the higher predisposition of women in their first pregnancies.

However, infection is rarely symptomatic in the newborn. The parasite most often disappears from peripheral blood within days, without treatment. This "natural resistance" of the newborn to malaria infection depends on two factors: trans-placental transmission of maternal $\mathrm{IgG}$ antibodies and the presence of hemoglobin $\mathrm{F}(\mathrm{Hb} F)$ all of which adversely affects the growth of P. falciparum in RBCs [52]. Maternally derived IgG antibodies are known to provide protection against many infectious diseases, including clinical malaria, for periods up to 9 months in neonates and infants, although the precise mechanism for this protection is still unclear[59]. This protective role by transplacentally acquired antibodies to malaria during the first few months of life has also been put to question in other studies $[60,61]$.

Breastfeeding could be an additional element of protection and this could be due to several factors. There is a defi- 
ciency of para-amino benzoic acid in breastmilk which is necessary for the synthesis of deoxyribonucleic acid (DNA) of plasmodium thus inhibiting multiplication of the parasite. Also, the presence of lactoferrin and immunoglobulin A (IgA) in breast milk have been shown to inhibit P. falciparum in vitro [29, 52, 59].

The newborn is thus relatively protected from the interactions of the parasite with syncytiotrophoblast receptors; transplacental passage of maternal antibodies; unfavorable conditions for parasite growth caused by the presence of $\mathrm{HbF}$; and deficiency in para-amino benzoic acid in breastmilk.

\section{CONCLUSION}

Although malaria is still a deadly disease in most parts of the world, natural defense mechanisms as described in the review exist in the body and contribute to controlling the disease burden. These mechanisms vary from one person to another thus determining individual susceptibility to severe forms of the disease and may positively moderate severity of illness and the risk of mortality. This paper reviewed the contribution of hemoglobinopathies, enzyme deficiencies and epidemiological factors such as age and endemicity to the survival of human beings in malaria infested areas. Although the mechanism and physiology may vary, the common factor to these innate and acquired states is that they offer protection from severe malaria and its complications. In-depth understanding of these defense mechanisms may open pathways for further research on the development of malaria vaccines and more effective malaria treatments. However, given the variability in effectiveness of these natural defenses, efforts should be placed on preventive measures to reduce morbidity and mortality especially in high risk groups such as children under 5 years of age and pregnant women.

\section{LIST OF ABBREVIATIONS}

\begin{tabular}{|c|c|c|}
\hline $\mathrm{RBC}$ & $=$ & Red blood cell \\
\hline pfEMP & $=$ & $\begin{array}{l}\text { Plasmodium falciparum erythrocyte } \mathrm{m} \\
\text { brane protein }\end{array}$ \\
\hline G6PD & $=$ & Glucose 6 phosphate dehydrogenase \\
\hline ATP & $=$ & Adenosine triphosphate \\
\hline ADCI & $=$ & Antibody dependent cellular inhibition \\
\hline ADCC & $=$ & Antibody dependent cytotoxicity \\
\hline HIV & $=$ & Human immuno deficiency virus \\
\hline DNA & $=$ & Deoxyribonucleic acid \\
\hline SCD & $=$ & Sickle cell disease \\
\hline SSA & $=$ & Sickle cell anemia \\
\hline
\end{tabular}

\section{CONFLICT OF INTEREST}

The authors confirm that this article content has no conflicts of interest.

\section{ACKNOWLEDGEMENT}

Declared none.

\section{REFERENCES}

[1] WHO. World Malaria Report 2011. Available at: http://www.who.int/malaria/ world_malaria_report_2011/en/index.html [Accessed Jan, 11, 2012].

[2] Ogobara D. Erythrocyte polymorphism in Mali: epidemiology and resistance mechanisms against severe Plasmodium falciparum malaria. Bull Acad Natl Méd 2007; 191: 783-4.

[3] Janse CJ, Waters AP. The exoneme helps malaria parasites to break out of blood cells. Cell 2007; 14; 131(6): 1036-8.

[4] Tilley L, McFadden G, Cowman A, Klonis N. Illuminating Plasmodium falciparum-infected red blood cells. Trends Parasitol 2007 , 23(6): 268-77.

[5] Cooke BM, Mohandas N, Coppel RL. Malaria and the red blood cell membrane. Semin Hematol 2004; 41(2): 173-88.

[6] WHO. Sickle cell prevention and control. Available at: http://www.afro.who.int/en/clusters-a-programmes/dpc/noncommunicable-diseases-managementndm/programmecomponents/sickle-cell-disease.html [Accessed : 25 september, 2012].

[7] Barrère J. Le phénotype drépanocytaire. Available at : http://www.inrp.fr/Acces/biotic/gpe/ dossiers/drepanocytose/ht$\mathrm{ml} /$ synthese.htm. [Accessed: 10 Jan, 2011].

[8] Labie D. Hémoglobinopathies et paludisme à Plasmodium falciparum: un exemple d'effet épistatique négatif. Santé 2006; 16: 26970 .

[9] Nau J-Y. Nouvelles lumières sur les liens paludisme-thalassémie. Rev Med Suisse 2008; 4: 810

[10] Pasvol G. Cellular mechanisms of protection by sickle cell trait \& thalassemia against malaria. Available at: http://www.bbts.org.uk/PDFs/events $/ 5 \% 20 \% 20 \mathrm{Geoff} \quad \% 20$ Pasvol\%20DEGANWY\%20133022222.pdf . [Accessed: 21 May, 2011].

[11] Roberts DJ. Protection against malaria in the hemoglobinopathies. Available at: http://www.uptodate.com/contents/protection-againstmalaria-in-the-hemoglobinopathies. [Accessed 23 June, 2011].

[12] Horrocks P, Pinches RA, Chakravorty SJ, et al. PfEMP1 expression is reduced on the surface of knobless Plasmodium falciparum infected erythrocytes. J Cell Sci 2005; 118: 2507-18.

[13] Nagel RL, Labie D. La résistance innée au paludisme due aux anomalies de l'hémoglobine. Hématologie 2002; 8: 405-13.

[14] Lang F, Lang PA, Lang KS, et al. Channel- induced apoptosis of infected host cells - the case of malaria. Eur J Physiol 2004; 448: $319-24$.

[15] Malaria and the red cell. Available at: http://www.sickle.bwh.harvard.edu/malaria_sickle.html. [Accessed 25 May, 2011].

[16] López C, Saravia C, Gomez A, Hoebeke J, Patarroyo MA. Mechanisms of genetically-based resistance to malaria. Gene 2010; 467: 1-12.

[17] Gong L, Maiteki-Sebuguzi C, Rosenthal PJ, et al. Evidence for both innate and acquired mechanisms of protection from Plasmodium falciparum in children with sickle cell trait. Blood 2012; 119(16): 3808-14.

[18] Fairhurst RM, Baruch DI, Brittain NJ, et al. Abnormal display of PfEMP-1 on erythrocytes carrying haemoglobin $\mathrm{C}$ may protect against malaria. Nature 2005; 435: 1117-21

[19] Séidina Aboubacar SD. Les mécanismes de protection de l'hémoglobinose $\mathrm{C}$ contre les formes graves de paludisme à Plasmodium falciparum : résultats d'études in vitro. Thèse de Docteur en Pharmacie (Diplôme d'Etat) 2004-2005. Faculté de Médecine, de Pharmacie et d'Odonto-Stomatologie du Mali.

[20] Agarwal A, Guindo A, Sissoko Y, et al. Hemoglobin C associated with protection from severe malaria in the Dogon of Mali, a West African population with a low prevalence of hemoglobin S. Blood 2000; 96: 2358-63

[21] Diallo DA, Doumbo OK, Dicko A, et al. A comparison of anemia in hemoglobin $\mathrm{C}$ and normal hemoglobin A children with Plasmodium falciparum malaria. Acta Trop 2004; 90: 295-9.

[22] Rihet P, Flori L, Tall F, Traore AS, Fumoux F. Hemoglobin C is associated with reduced Plasmodium falciparum parasitemia and low risk of mild malaria attack. Hum Mol Genet 2004; 13: 1-6.

[23] Duflo B, Maïga L, Pichard E, et al. L'hémoglobinose C en milieu hospitalier Bamakois(Mali). Bull Soc Path Exot 1985; 78: 393-400. Rowe JA, Moulds JM, Newbold CI, Miller LH. P. falciparum rosetting mediated by a parasite-variant erythrocyte membrane protein and complement-receptor 1 . Nature $1997 ; 388: 292-5$. 
[25] Olson JA, Nagel RL. Synchronized culture of P. falciparum in abnormal RBCs: the mechanism of the inhibition of growth in HbCC cells. Blood 1986; 67: 997-1001.

[26] Pasvol G, Wilson RJ. The interaction of malaria parasite with RBCs. Br Med Bull 1982; 38: 133-40.

[27] Mockenhaupt FP, Ehrhardt S, Cramer JP, et al. Hemoglobin C and resistance to severe malaria in Ghanaian children. J Infect Dis 2004; 190: 1006-7.

[28] Ohls RK, Christensen RD. Diseases of the blood. In: Behrman RE, Kleegman RM, Eds., Nelson Textbook of Pediatrics. $18^{\text {th }}$ ed. Amstram: Saunders/Elsevier, 2007; pp. 1997-2095.

[29] Le Hesran J-Y. Les particularités du paludisme de l'enfant. Med Trop 2000; 60: 92-8.

[30] Eridani S. Sickle cell protection from malaria. Hematol Rep 2011; 3(3): e24.

[31] OMS. Répartition géographique du déficit en G6PD dans le monde. Available at: http://www.gs-im3.fr/G6PD/G6PDdistribution.html. [Accessed 15 May, 2011].

[32] Wajcman H, Galactéros F. Le déficit en glucose-6 phosphate déshydrogénase : protection contre le paludisme et risque d'accidents hémolytiques. C. R. Biol 2004; 327: 711-20.

[33] Vidal R. Médicaments et déficit en G6PD. Vidal 2011; 1-4.

[34] Cappellini MD, Fiorelli G. Glucose-6-phosphate dehydrogenase deficiency. Lancet 2008; 371: 64-74.

[35] Cappadoro M, Giribaldi G, O'Brien E, Turrini F, Mannu F, Ulliers D. Early phagocytosis of Glucose-6-Phosphate Dehydrogenase (G6PD)-Deficient erythrocytes parasitized by Plasmodium falciparum may explain malaria protection in G6PD deficiency. Blood 1998; 92(7): 2527-34.

[36] Guindo A, Fairhurst RM, Doumbo OK, Wellems TE, Diallo DA. $\mathrm{X}$-linked G6PD deficiency protects hemizygous males but not heterozygous females against severe malaria. PLoS Med 2007; 4(3): e66.

[37] Clark TG, Fry AE, Auburn S, et al. Allelic heterogeneity of G6PD deficiency in West Africa and severe malaria susceptibility. Eur J Hum Genet 2009; 17: 1080-5.

[38] Dean L. Antigen Duffy. In: Blood groups and red cell antigens. Bethesda (MD): National Center for Biotechnology Information (US); 2005.

[39] Malaria history. Available at: http://www.news-medical.net/hea1th/Malaria-History.aspx. [Accessed 25 Jan, 2011].

[40] King CL, Adams JH, Xianli J, et al. Fy(a)/Fy(b) antigen polymorphism in human erythrocyte Duffy antigen affects susceptibility to Plasmodium vivax malaria. Proc Natl Acad Sci USA 2011; 108(50): 20113-8

[41] Rowe JA, Handel IG, Thera MA, et al. Blood group O protects against severe Plasmodium falciparum malaria through the mechanism of reduced rosetting. Proc Natl Acad Sci 2007; 104: 17471-6.

[42] Pathirana SL, Alles HK, Bandara S, et al. ABO-blood-group types and protection against severe, Plasmodium falciparum malaria. Ann Trop Med Parasitol 2005; 99: 119-24.

[43] Panda AK, Panda SK, Sahu AN, Tripathy R, Ravindran B, Das BK. Association of ABO blood group with severe falciparum malaria in adults: case control study and meta-analysis. Malar J 2011; 10: 309 .

[44] Tekeste Z, Petros B. The ABO blood group and Plasmodium falciparum malaria in Awash, Metehara and Ziway areas, Ethiopia. Malar J 2010; 9: 280 .
[45] Rowe JA, Opi DH, Williams TN. Blood groups and malaria: fresh insights into pathogenesis and identification of targets for intervention. Curr Opin Hematol 2009; 16(6): 480-7.

[46] Lagardère B. Le paludisme de l'enfant. Médecine Thérapeutique 2002; 8: 140-5

[47] Hill AVS, Allsopp CEM, Kwiatkowski D, et al. Common West African HLA antigens are associated with protection from severe malaria. Nature 1991; 352: 505-600.

[48] Hill AVS, Elvin J, Willis AC, et al. Molecular analysis of the association of HLA-B53 and resistance to severe malaria. Nature 1992; 360: 435-9.

[49] Roll Back Malaria. Qu'est-ce que le Paludisme. Available at: http://www.rollbackmalaria.org/cmc_upload/0/000/015/372/RBMInfosheet $1 \mathrm{fr} . \mathrm{htm}$. [Accessed 20 June, 2011].

[50] Obi RK, Okangba CC, Nwanebu FC, Ndubuisi UU, Orji NM. Premunition in Plasmodium falciparum malaria. Afr J Biotechnol 2010; 9: 1397-401.

[51] Boudin C, Baudon D, Devoucoux R. Immunologie du paludisme : Les relations hôte-parasite dans l'infection paludéenne. Etudes Médicales 1984; 2: 91-104. [Accessed 2 May, 2011].

[52] Imbert P, Minodier P. Paludisme de l'enfant. Encyclopédie Médico-Chirurgicale. EMC (Elsevier Masson SAS), Maladies infectieuses, 8-507-A-30, 2011

[53] Barfoda L, Dalgaarda MB, Plemana ST, Ofori MF, Pleass RJ, Hviid L. Evasion of immunity to Plasmodium falciparum malaria by IgM masking of protective IgG epitopes in infected erythrocyte surface-exposed PfEMP1. Proc Natl Acad Sci USA 2011; 108(30): 12485-90.

[54] Duffy MF, Caragounis A, Noviyanti R, et al. Transcribed var genes associated with placental malaria in Malawian Women. Infect Immun 2006; 74(8): 4875-83.

[55] Sander AF, Salanti A, Lavstsen T, et al.Positive selection of Plas modium falciparum parasites with multiple var2csa-type PfEMP1 genes during the course of infection in pregnant women. J Infect Dis 2011; 203: 1679-85.

[56] Tuikue Ndam NG, Salanti A, Bertin G, et al. High level of var2csa transcription by Plasmodium falciparum isolated from the placenta. J Infect Dis 2005; 192: 331-5.

[57] Rovira-Vallbona E, Dobaňo C, Bardaji A, et al. Transcription of var genes other than var2csa in Plasmodium falciparum parasites infecting Mozambican pregnant women. J Infect Dis 2011; 204: 27-35.

[58] Mayor A, Rovira-Vallbona E, Machevo S, et al. Parity and placental infection affect antibody responses against Plasmodium falciparum during pregnancy. Infect Immun 2011; 79(4): 1654-9.

[59] Riley EM, Wagner GE, Akanmori BD, Korame KA. Do maternally acquired antibodies protect infants from malaria infection? Parasite Immunol 2001; 23: 51-9.

[60] Riley EM, Wagner GE, Ofori MF, et al. Lack of association between maternal antibody and protection of African infants from malaria infection. Infect Immun 2000; 68: 5856-63.

[61] Achidi EA,Salimonu LS, Perlmann H, Perlmann P, Berzins K, Williams AI. Lack of association between levels of transplacentally acquired Plasmodium falciparum-specific antibodies and age of onset of clinical malaria in infants in a malaria endemic area of $\mathrm{Ni}$ geria. Acta Trop 1996; 61: 315-26.

Received: June 06, 2013

Revised: July 29, 2013

Accepted: August 05, 2013

(C) Chiabi et al.; Licensee Bentham Open.

This is an open access article licensed under the terms of the Creative Commons Attribution Non-Commercial License (http://creativecommons.org/licenses/by-nc/3.0/) which permits unrestricted, non-commercial use, distribution and reproduction in any medium, provided the work is properly cited. 